\author{
Ilya Vasilyev, Margarita Izmalkova, Raisa Khalatova
}

\title{
The Views of the Court of Arbitration for Sport and the Austrian Football Association on legal liability for the conduct of supporters
}

\section{Introduction}

Nowadays football matches are enormous events which are closely watched by millions of people worldwide. Since supporters enthusiastically cheer for their favorite teams, sports offenses have become common in the football world. The misbehavior of supporters interferes with matches and creates areas of conflict between rival football fans of different teams. To prevent this, frameworks of proper conduct are being established through national statutes in multiple jurisdictions, the violation of which can result in sanctions. The regulation of supporters' behavior is under the jurisdiction of both the legislator and sports organizations. The principle of "strict liability" is being used to combat hooliganism in front of both the national organizations and the Union of European Football Associations (henceforth - UEFA). According to Art. 8 of the UEFA Disciplinary Regulations (henceforth - Disciplinary Regulations), a football club is responsible for its players, members, officials or supporters if a rule of conduct is violated as a result of their actions, even if it can prove the absence of any fault or negligence. Any uncertainty regarding the affiliation of a supporter who has committed an offense before, during or after a match, is increasingly becoming a frequent focus of the jurisdiction of UEFA and may subsequently turn into an appeal in the Court of Arbitration for Sport (henceforth - CAS). Furthermore, the application of the principle of the appropriate sanction constantly remains under the discussion of the bodies of UEFA and CAS. Due to the fact that there is no definition of the term "supporter" in the Disciplinary Regulations, national associations and football clubs try to prove that the violators are not their supporters and, therefore, insist on the exemption and lifting of the sanctions applied.

In the current context of globalization, not only institutes of the national legal systems but also the regulatory institutions for the supranational sports organizations have started to become the objects of borrowing and repetition. These institutions follow the model of strict liability of clubs for the supporter's behavior, used by the national football or- 
ganizations on the basis of the legal concept, applied consistently within the decision of UEFA. The duty of clubs to interact with their supporters serves as a preventive function to avoid a supporter's unacceptable behavior. According to the position of the CAS, formed in a certain number of its decisions, through holding sports clubs accountable, strict liability is aimed at supporters whose conduct during sports events might be banned by the provisions of sports regulations. And as a result, the establishment of the presence or absence of any form of guilt of the club is not legally significant for such a model of responsibility. UEFA's approach to regulating the subjects of responsibility assumes that supporters remain outside the validity of the legal regulations of the sports organizations both because of the difficulty in identifying them and because of the lack of a developed mechanism for the realization of such jurisdictional activity in sports organizations. However, some national football associations demonstrate regulation and that they hold supporters responsible for actions committed during the football competition. For example, the position of the Austrian Football Association set out in the provisions of the Regulations of prohibited activities at the stadium (henceforth - the Regulations of prohibited activities). ${ }^{1}$ According to these Regulations, the Bundesliga, which is operates under the auspices of association, has the right to develop and to use its own regulations for the procedure of imposing bans on supporters visiting the places where a sporting event takes place.

The Russian Football Union and football clubs only have the right to hold spectators liable for their unacceptable behavior during a football match through the court. It is worth mentioning that now the judicial prospects for holding spectators liable appear to be vague and there is no established practice on this issue. ${ }^{2}$ With regard to the Austrian Football Association, its approach is based on its right to hold the supporters accountable and to apply the proper sanctions to them, such as the ban for a certain period on visiting football matches under the jurisdiction of the association. In particular, the provisions of paragraph 112 of the Rules of the Austrian Football Association for the Administration of Justice ${ }^{3}$ determine that at least a two-year ban is applicable for supporters who have demonstrated racist behavior during the match. ${ }^{4}$

1 ÖFB-Stadionverbotsordnung [access: 1. Juli 2016], http://www.oefb.at/_uploads/_elements/70385_OEFB-Stadionverbotsordnung\%20gueltig\%20ab\%201.7.2016\%20EF.pdf [access: 10.12.2017].

2 Moscow oblast Court's Appeal Decision no. 33-10571/2014, http://www.consultant.ru/cons/ cgi/online.cgi?req=home\&utm_csource=online\&utm_cmedium=button [access: 10.12.2017].

3 ÖFB-Rechtspflegeordnung [access: 01.07.2017], http://www.oefb.at/show_a.php?t=elements $\& e=26943$ [access: 10.12.2017].

$4 \S 112$ (5) ÖFB-Rechtspflegeordnung [access: 01.07.2017], http://www.oefb.at/show_a. php?t=elements\&e=26943 [access: 10.12 .2017 ]. 
The Views of the Court of Arbitration for Sport and... $\mid 355$

\section{The Austrian Football Association Regulation of the Legal Liability of Supporters}

According to the preamble of the Regulation of prohibited activities, the rules of this act are aimed at supporters whose behavior violates the order of sports competitions. The jurisdiction policy of the Austrian Football Association in relation to the supporters is based on the discretionary choice by the Committee for Stadiums, Security, and Supporters ${ }^{5}$ between giving the supporters a warning or a prohibition on attending sports events at any stadiums located on the territory of the association's functioning. The imposition of a ban as a sanction is motivated by the need to ensure the safety of supporters, and also for the protection of the stadium's infrastructure. According to the Austrian Football Bundesliga's Safety Regulations ${ }^{6}$ it is the club-organizer's ${ }^{7}$ responsibility to prevent persons supporters who have been banned from entering stadiums. However, the application of the ban is due to the justification of such a sanction from the point of view of general legal principles of objectivity and proportionality. For example, the application of the warning will be a proportionate sanction only if it is the first occurrence of such behavior on the part of the supporter which threatens public order or security. ${ }^{8}$ A warning can only be issued once to the same person for unacceptable behavior at the stadium. At the same time, the fiction of an unrepentant subject after a certain period of time is not used. The ban on a supporter attending stadiums is conditional on his actions being included in the prohibited behavior described on a closed list ${ }^{9}$. Some of the corpus delicti make the supporter liable as a result of the first accusation, and some of them only on the basis of a repeated violation. In particular, the first group includes: the presence or the use of pyrotechnics, laser pointers; racist or discriminatory behavior; and behavior that is would lead to unfavorable, high financial consequences for the club or the stadium. The second group includes aggressive behavior towards players, functionaries, officials, judges, government officials and other supporters (paragraph "a"), and repetition of behavior that previously led to the application of the ban. It should be noted that the responsibility of supporters for behavior at a sports competition is traditionally associated with public administrative regulation, and, in particular, with

5 Komitee für Stadien, Sicherheit und Supporterwesen» in ÖFB-Rechtspflegeordnung.

6 Sicherheitsrichtlinien für die bewerbe der Österreichischen Fussball-Bundesliga, http://www. bundesliga.at/de/tipico-bundesliga/uebersicht [access: 10.12.2017].

$7 \S 12$ Zuschauerkontrolle, Sicherheitsrichtlinien für die bewerbe der Österreichischen FussballBundesliga, http://www.bundesliga.at/de/tipico-bundesliga/uebersicht [access: 10.12.2017].

$8 \S 6$ Verwarnung, ÖFB-Stadionverbotsordnung, http://www.oefb.at/_uploads/_elements/70385_OEFB-Stadionverbotsordnung\%20gueltig\%20ab\%201.7.2016\%20EF.pdf [access: 10.12.2017].

$9 \S 5$ Anlass, Art und Dauer des Stadionverbots, ÖFB-Stadionverbotsordnung, http://www. oefb.at/_uploads/_elements/70385_OEFB-Stadionverbotsordnung\%20gueltig\%20ab\%20 1.7.2016\%20EF.pdf [access: 10.12.2017]. 
administrative legislation. For example, the sanction of a ban on visiting places where official sports competitions are held is presented in part 1,2 art. 20.31 of the Code of the Russian Federation on Administrative Offenses and its implementation is carried out by the organizers of competitions. Consequently, if the club-organizer recognizes a person in relation to whom there is court decision on administrative prohibition, the club has the right to refuse admittance to the supporter at the entrance or to remove him or her from the venue of the competition ${ }^{10}$. In this case, the supporter is not refunded the cost of the canceled ticket. A similar obligation to control persons wishing to participate in a sports competition as a supporter is placed on the club-organizer of matches in the Austrian Football Bundesliga. ${ }^{11}$ The organizing club, when using the right to provide screening procedures granted to it, must not admit supporters who are prohibited from visiting stadiums under the jurisdiction of the Austrian Football Association on the territory of the stadium. The prohibition in the Russian regulation model extends only to official competitions, while the sanction applied on the basis of the Regulation on prohibited actions prevents a person from visiting any stadiums on the territory of the association, regardless of the status of the competition. Currently, in the Russian Football Championship (RFPL) interesting club statements can be noticed, namely concerning the use of opportunities provided by Russian civil legislation to prevent certain persons, established by the club as participants in unacceptable behavior, from attending football matches when the club acts as an organizer. For example, the football club "Krasnodar"12 used the fact that several supporters had been brought to administrative responsibility for violating behavior ${ }^{13}$ and deprived the supporters of the right to visit home matches for a certain period. ${ }^{14}$ The club intends to consider the next instance of these persons being brought to administrative responsibility for similar actions as the basis for a lifetime deprivation of their right to attend matches of which the club is the organizer. However, in the present example, the legitimization of the club's position is conditioned by Russian civil law, specifically - a public service contract, the point of which is not to bring a certain individual - a supporter - to responsibility in extrajudicial procedure and apply

$10 \S 6$ Act of the Russian Government on 16.12.2013 no. 1156 "Rules of conduct for supporters at official sports competitions", http://www.consultant.ru/cons/cgi/online.cgi?req=home\&utm_ csource=online\&utm_cmedium=button [access: 10.12.2017].

$11 \S 12$ (4) Zuschauerkontrolle, Sicherheitsrichtlinien für die bewerbe der Österreichischen Fussball-Bundesliga, http://www.bundesliga.at/de/tipico-bundesliga/uebersicht [access: 10.12.2017].

12 Krasnodar FC supporters were banned for a year to attend home games after a fight with the supporters Anzhi FC, https://www.sports.ru/football/1050866272.html [access: 10.12.2017].

13 Art. 20.31 Code of the Russian Federation on Administrative Offenses, http://www.consultant.ru/cons/cgi/online.cgi?req=home\&utm_csource=online\&utm_cmedium=button [access: 10.12.2017].

14 Apparently, the club used as a basis for its own ban the decision against the supporters in the case of an administrative violation, which did not imply a ban for visiting official sports competitions for a certain period. 
a sanction consisting in limiting his or her individual rights and freedoms. At the same time, the application - not by the public authority but by the sports organization - of the ban on visiting sporting events at any stadiums of the association does not mean a reduction in the level of protection provided for the person being brought to justice. As follows from the provisions of paragraph 7 of the Regulations of prohibited actions ${ }^{15}$, the supporter has the right to appeal against the decision of the Austrian Football Association to the appellate instance ${ }^{16}$ of this sports organization while retaining the sanction for the review period. With regard to safeguarding the interests of a prosecuted supporter, one should also consider the right of the Stadium, Safety and Supporters Committee to curtail or abolish the prohibition applied to a person in the presence of exceptional circumstances. These can include, in particular, the nature and exceptional circumstances of the deed, the confession of guilt by a person brought to justice, and also his or her young age. In this case, the list of exceptional circumstances in the provisions of the Regulation of banned actions is left open and allows the jurisdictional body of the association to establish other circumstances indicating that there is no risk of the supporter's unacceptable sporting behavior being repeated. The presence in the criminal law of Austria of the institution of the responsibility of the supporter for conduct during a football match significantly affects the application of the prohibition by the jurisdiction of the football association, because it uses the prejudice criterion in the following sense. As follows from the provisions of paragraph 9 of the Regulations of prohibited actions, the ban on the supporter appointed by the Committee for Stadiums, Security and the Supporters is subject to immediate cancellation if the fact of the termination of criminal prosecution of this person, or the existence of the verdict of not guilty which has taken legal effect, are established. The burden of proof of both facts, as is apparent from the regulatory act under consideration, is assigned to the supporter. However, if the termination of criminal prosecution on non-rehabilitating grounds is established (for example, the insignificance of the act committed), the Committee on Stadiums, Security and the Supporters does not have a normative obligation to repeal the ban previously applied to the supporter. Jurisdictional authority if the criminal prosecution is terminated for the reasons mentioned, at the request of the supporter, only checks the proportionality of the term of the ban applied. ${ }^{17}$

$15 \S 7$ Rechtsmittel, ÖFB-Rechtspflegeordnung [access: 01.07.2017], http://www.oefb.at/show_a. php?t=elements\&e=26943 [access: 10.12.2017].

16 Rechtsmittelsenat.

$17 \S 9$ Aufhebung eines bestehenden Stadionverbotes, ÖFB-Rechtspflegeordnung [access: 01.07.2017], http://www.oefb.at/show_a.php?t=elements\&e=26943 [access: 10.12.2017]. 


\section{Using a Model of Strict Liability for the Behavior of Supporters}

The classical strict responsibility of clubs for the supporters' behavior is established in the provisions of the Regulations of the Austrian Football Association on bringing offenders to justice. The range of offenses committed by clubs related to the behavior of supporters is determined in accordance with the regulations of FIFA and UEFA, and is presented in a closed list. In particular, paragraph $116^{18}$ establishes both the responsibility of the club-organizer and the guest club for the use of pyrotechnics used by the supporters (the ban on the use of pyrotechnics is established by the Safety Rules of the Austrian Football Bundesliga ${ }^{19}$ ). Comparing the level of sanctions for such an offense, one can notice a broader discretion of the UEFA jurisdictional bodies when it comes to choosing from the extensive list of sanctions stipulated in part 1 art. 6 of the Disciplinary Regulations. The range of sanctions used by the association is limited to a fine of a certain range, either by partial closure of the stadium sectors, or the disqualification of the stadium. The association's rules do not use the concept of conditional sanctions ${ }^{20}$, which is used in the UEFA Disciplinary Regulations to individualize the cases of bringing the club to justice. Most of the sanctions, listed in the provisions of art. 6 of the regulations, may be conditional on the discretion of the jurisdictional body. However, the application of conditional sanctions cannot be used consistently in law enforcement practice, since it creates the danger of misleading both clubs and supporters. Any case of using a conditional sanction by the jurisdictional authority means doubts about the significance of the charge brought against the club. Each precedent of this kind gives a completely unambiguous signal for clubs and supporters about the existence of a hypothetical opportunity to avoid both a serious sanction and the high level of such a sanction, which is unacceptable from the point of view of the goals of football ${ }^{21}$. At the same time, we should note that insufficient evidence cannot justify the use of conditional sanctions, since in this case it is not a question of the proportionality of the charge and the sanction, but in general of the assessment by the jurisdic-

$18 \S 116$ Verletzung der Veranstaltungsbestimmungen, ÖFB-Rechtspflegeordnung [access: 01.07.2017], http://www.oefb.at/show_a.php?t=elements\&e=26943 [access: 10.12.2017].

$19 \S 15$ Ausnahmeregelung Pyrotechnik, Sicherheitsrichtlinien für die bewerbe der Österreichischen Fussball-Bundesliga, http://www.bundesliga.at/de/tipico-bundesliga/uebersicht [access: 10.12.2017].

20 Sometimes in legal practice it is called a "conditional" sanction, vid., for example, the club's argument in the practices of UEFA legal bodies: Decision of 3 February 2015, Legia Warszawa S.A., Case Law Control, Ethics and Disciplinary Body \& Appeals Body. Season 2015/2016. January 2015 - June 2015, https:/www.uefa.com/insideuefa/disciplinary/disciplinary-cases/index.html [access: 10.12.2017].

21 This conclusion follows from the law enforcement practices of UEFA legal bodies: Decision of 3 February 2015, Legia Warszawa S.A., Case Law Control, Ethics and Disciplinary Body \& Appeals Body. Season 2015/2016. January 2015 - June 2015, https:/www.uefa.com/insideuefa/ disciplinary/disciplinary-cases/index.html [access: 10.12.2017]. 
tional body of the grounds for making the club responsible for the behavior of supporters. In the law enforcement practice of UEFA, there are precedents of the use of conditional sanctions in relation to clubs for the behavior of supporters and that is why the argumentation used is of particular interest. For example, in one of the cases ${ }^{22}$, the jurisdictional body noted as a basis for conditional sanction the measures taken by the club to control its supporters, including special actions in connection with the match between the clubs historical opponents. However, even the possible provocation of the supporters and the absence of previous cases of prosecution for the behavior of supporters was not considered by the body in justifying the proportionality of the chosen conditional sanction - half of the imposed fine with a probation period of two years.

The responsibility of the club-organizer of the match in connection with improper preparation and holding the sports competition should be distinguished from the responsibility of the club-organizer for the behavior of the supporters. If in the first situation the responsibility of the club is of a classic character, determined by the presence of guilt, then in the second case strict liability is applied. This attitude is demonstrated in the UEFA Disciplinary Regulations ${ }^{23}$ and is also used in the regulatory acts of the Austrian Football Association. It should be noted that appropriate performance of the duties assigned to the club-organizer by standards of regulations in many respects has a preventive character in relation to the unacceptable behavior of supporters. One of the fundamental foundations for the prevention of conflict situations at the stadium is the division of the supporters into the sectors of the guest club and the organizing club. For this purpose at the level of UEFA and national association there is a ticket order, including a detailed algorithm of the request by club-guest from club-organizer for a certain number of tickets within a quota. The distribution by the club-guest of the received tickets guarantees the distinction of the affiliation of these supporters with the club and the possibility of identifying everyone who received such a ticket ${ }^{24}$. Nevertheless, the policy of dividing the supporters into sectors can be abused by the individual reselling, which, of course, is not aimed at dividing the supporters of the two teams. The Austrian Football Association obliges the club-organizer to counter uncontrolled ticket sales by third parties. The club, which has such status, as it follows from the provisions

22 Decision of 19 May 2016, Manchester United FC, Case Law Control, Ethics and Disciplinary Body \& Appeals Body. Season 2015/2016. January 2016 - June 2016, https:/www.uefa.com/ insideuefa/disciplinary/disciplinary-cases/index.html [access: 10.12.2017].

23 Art. 16 (1), 16 (2) UEFA Disciplinary Regulations, https://www.uefa.com/MultimediaFiles/ Download/Regulations/uefaorg/UEFACompDisCases/02/48/23/06/2482306_DOWNLOAD.pdf [access: 10.12.2017].

24 The payable or non-payable nature of the receipt of a ticket from the club-guest ticket does not affect the ability of the club to identify the supporters who accompany the club during the guest match. 
of the Austrian Football Bundesliga Security Regulations ${ }^{25}$, is obliged to develop and to use legal measures against the sale of tickets on the territory adjacent to the stadium. In the context of preventive measures regarding the unacceptable behavior of supporters, the responsibilities of the organizing club of the Bundesliga match for the inspection of supporters should be considered. The club has the responsibility not only to check all the supporters for active support sectors at the entrance to the stadium, including the sector of the club-guest ${ }^{26}$, and randomly check spectators in other sectors ${ }^{27}$, but also the responsibility to identify real or potentially dangerous supporters and not allow them into the stadium. ${ }^{28}$ The potential danger of supporters is caused by the state of alcoholic and narcotic intoxication. The identification of such a danger allows the club-organizer to refuse the supporter entrance to this match without compensation for the cost of the purchased ticket. Similar consequences can be expected if a supporter refuses to leave items which are banned from the stadium during the match at the entrance. ${ }^{29}$

\section{The Position of the CAS}

We will consider the practice of CAS, in particular CAS 2015/A/3874 Football Association of Albania v. the UEFA and the Football Association of Serbia ${ }^{30}$, as well as the practice of the UEFA Control, Ethics and Disciplinary Body, and the UEFA Appeals

$25 \$ 10$ (1) Maßnahmen in Verbindung mit Eintrittskarten, Sicherheitsrichtlinien für die bewerbe der Österreichischen Fussball-Bundesliga, http://www.bundesliga.at/de/tipico-bundesliga/uebersicht [access: 10.12.2017].

$26 \$ 12$ (1), \$12 (2) Zuschauerkontrolle, Sicherheitsrichtlinien für die bewerbe der Österreichischen Fussball-Bundesliga, http://www.bundesliga.at/de/tipico-bundesliga/uebersicht [access: 10.12.2017].

27 For example, the duty to carry out a personal inspection is entrusted to the organizing club and law enforcement bodies in the Russian jurisdiction. Compare: pp. "v" par. 4 of Act of the Russian Government on 16.12.2013 no. 1156 "Rules of conduct for supporters at official sports competitions": "Supporters in the conduct of official sports competitions are obliged ... when passing or passing to place the official sports competition and [or] around the stadium to undergo a personal inspection and provide personal items for inspection", http://www. consultant.ru/cons/cgi/online.cgi?req=home\&utm_csource=online\&utm_cmedium=button [access: 10.12.2017].

$28 § 12$ (4) Zuschauerkontrolle, Sicherheitsrichtlinien für die bewerbe der Österreichischen Fussball-Bundesliga, http://www.bundesliga.at/de/tipico-bundesliga/uebersicht [access: 10.12.2017].

29 The list of prohibited items is presented in $§ 13$ Verbotene Gegenstände, Sicherheitsrichtlinien für die bewerbe der Österreichischen Fussball-Bundesliga, http://www.bundesliga.at/de/ tipico-bundesliga/uebersicht [access: 10.12.2017].

30 Database of CAS awards, CAS 2015/A/3874 Football Association of Albania v. the UEFA and the Football Association of Serbia, http://jurisprudence.tas-cas.org/Shared\%20Documents/3874.pdf [access: 10.12.2017]. 
Body, which consistently and convincingly demonstrates the assessment of supporter's belonging to a club, including the situations involving the use of pyrotechnics from outside the stadium. These cases help both to qualify the responsibility of national associations and football clubs for the improper actions of supporters carried out remotely, with the help of various controlled technical means, and to order proportional sanctions.

In CAS 2015/A/3874 Football Association of Albania v. UEFA \& Football Association of Serbia (hereinafter - CAS 2015/A/3874), the Football Association of Albania (hereinafter - the FAA) stated that the decision of the UEFA Appeals Body that the drone with an illicit banner was controlled by an Albanian supporter was erroneous: no evidence was presented to confirm the affiliation of individuals to the FAA, besides, UEFA regulations do not contain any presumptions to identify the offender simply on the basis of the nature of the committed offense. It is possible that the drone could have been controlled by a person who was not a supporter of the FAA (for example, a Serbian supporter). These arguments are in fact aimed at excluding the responsibility of the club for the conduct of a perpetrator because it was impossible to prove his affiliation. As we know, the provisions of the Disciplinary Regulations do not provide the definition of "supporter", it is an open concept. ${ }^{31}$ For this reason, in the jurisdiction of the UEFA and CAS, neither citizenship, nor residence, nor the presence of a ticket, nor race, nor nationality is taken into account when proving that a supporter belongs to a national association or a football club. After analyzing the provisions of Disciplinary Regulations, one can indeed assert that there is no normatively defined algorithm for determining the supporter's affiliation to an association or a club. Such an algorithm has been developed in the enforcement practice of UEFA jurisdictions and is presented as "a reasonable and objective observer" proof model for the correct assessment of the situation and determining whether a person is a supporter of a club or not. The FAA took the position that the conclusions from the cases on which the decision of the UEFA Appeals Body was based (CAS 2007/A/1217 Feyenoord Rotterdam v. UEFA ${ }^{32}$; CAS 2013/A/3139 Fenerbahçe SK v. UEFA ${ }^{33}$; CAS 2013/A/3324 GNK Dinamo v. UEFA and CAS 2013/A/3369 GNK Dinamo v. $\mathrm{UEFA}^{34}$ ) do not correspond to the principle of relevance to the case, because

31 About the various concepts of "supporter" vid. also: I.A. Vasilyev, A.A. Kashaeva, The sporting responsibility of football clubs for offensive behavior of supporters on the basis of pp."e" p. 2 Art. 16 UEFA Disciplinary Regulations and Art. 112, Art. 116 Russian Football Union (RFU) Disciplinary Regulations, "Petersburg Lawyer" 2017, no. 2, pp. 60-73.

32 Database of CAS awards, CAS 2007/A/1217 Feyenoord Rotterdam v. UEFA, http://jurisprudence.tas-cas.org/Shared\%20Documents/1217.pdf [access: 10.12.2017].

33 Database of CAS awards, CAS 2013/A/3139 Fenerbahçe SK v. UEFA, http://jurisprudence.tascas.org/Shared\%20Documents/3139.pdf [access: 10.12.2017].

34 Decisions issued by the Court of Arbitration for Sport in cases involving UEFA, CAS 2013/A/3324 GNK Dinamo v. UEFA and CAS 2013/A/3369 GNK Dinamo v. UEFA, http:// www.uefa.com/MultimediaFiles/Download/uefaorg/CASdecisions/02/47/25/32/2472532 DOWNLOAD.pdf [access: 10.12.2017]. 
in these cases the location of supporters was identified. There is no such certainty in the case CAS 2015/A/3874. For example, in the case CAS 2007/A/1217 the UEFA jurisdictional body concluded that "the behavior of individuals and their location in the stadium and its vicinity are important criteria for determining which team or club they support". In CAS 2015/A/3874 there were no Albanian supporters at the stadium or anywhere near the stadium, and therefore the precedence nature of the decision is in question. In another case, CAS 2013/A/3139, there was no doubt that the fireworks during the match behind closed doors were launched by the supporters of the host team. However, in the case in question, CAS 2015/A/3874, it is not clear and it is not established who launched the drone. Finally, CAS 2013/A/3324\&3369 emphasizes the principle of strict liability in a situation where supporters are physically present at the stadium and can be clearly identified as supporters of the host team.

According to the FAA, in CAS 2015/A/3874 the principle of strict liability cannot be applied since in this situation even the offender's location could not have been analyzed. ${ }^{35}$ Even if there was such a presumption in the Disciplinary Regulations, it could not have been applied, because there was no evidence of the presence of Albanian supporters around the stadium, as required by Art. 16 of the Disciplinary Regulations. In the view of the FAA, attributing the operation of the drone to Albanian supporters under those circumstances "would be at odds with Swiss law as there is no minimum connection between the FAA and the unknown individuals who operated the drone". In addition, the appellant submitted an expert opinion based on three conclusions. Firstly, the concept of "supporter" has a weak connection between the association and the person who committed the offense. Secondly, some of the presumptions used in UEFA jurisdictions' practice are acceptable, but still they should be based on reasonable and objective criteria (for example, individuals seated in a designated area of the stadium can be deemed to be a supporter of a particular team), and are rebuttable. Finally, failing such a minimum connection means that the individual cannot be characterized as a "supporter" for the purposes of disciplinary sanctions against the association. Thus, according to the FAA, the use of a drone and banner cannot be the result of the actions of association supporters, since the image of the sign supporting the team is not sufficient for determining the identity of the offender. Holding otherwise would lead to an arbitrary decision and dangerous precedent, because, as the FAA notes, “....it would become

35 Interesting arguments about influence of supporter's location on the responsibility of a national association or a club are used in the research of de M.A. Vlieger. See: de M.A. Vlieger, Racism in European football: going bananas? An analysis of how to establish racist behaviour by football supporters under the UEFA disciplinary regulations in light of the inflatable banana-case against Feyenoord, "International Sports Law Journal" 2016, vol. 15, issue 3-4, pp. 226-232. 
an easy game to harm any team by operating a drone from a distance with symbols or signs supporting that same team".

UEFA, in turn, in CAS 2015/A/3874, proved that the drone had been managed by A1banian supporters from the perspective of "a reasonable and objective observer", on the basis of a comprehensive review. First, it is necessary to pay attention to the content of the banner, in particular, the map of "Great Albania" and Albanian nationalist symbols. Secondly, the reaction of Albanian players and FAA officials, who tried to reclaim and keep the banner from the Serbian players, is indicative. Thirdly, the subsequent appearance of the same banner in other matches and events should be taken into consideration.

In its practice, namely in CAS 2007/A/1217, arbitration noted that the behavior of supporters, their location in and around the stadium, are essential criteria for determining which team or club they support. In addition, CAS confirmed that supporters do not need to be at the stadium or to be kept in sight. An association or a club becomes responsible for its supporters' misbehavior as long as the incident takes place at a match, even if the supporters are not present within the stadium. The use in the provisions of Disciplinary Regulations, in particular in the provisions of Art. 16, of the expression "at a match" implies the misconduct of supporters that can influence the smooth running of the game. In the case under consideration, it is obvious that the fireworks launched by supporters had a negative impact on the smooth running of the match because the referee felt obliged to interrupt the game for a short time. The link between the negative influence of supporters on the match, and the need for a temporary suspension or final termination because of this, was established by the arbitration in CAS 2013/A/3139.

Another issue assessed by CAS was the control of the drone by a supporter of one of the teams. Considering the version about the participation of the FAA's supporter in this situation, the arbitration drew attention to four points. First, approximately 100 people associated with the appellant attended the stadium. Secondly, a remote control used to manage such a drone is a small device that can be easily hidden during the inspection at the entrance to the stadium. Thirdly, after the abandonment of the match, the Serbian police searched the FAA's delegation and the dressing rooms but it did not frisk the whole group of Albanians present in the stands. Finally, the drone could have been managed by an Albanian supporter outside the stadium. In the end, CAS, having considered the situation from the perspective of "a reasonable and objective observer", concluded that Albanian supporters controlled the drone. The arbitration considered the nature of the symbols and words depicted on the banner, the positive reaction of Albanian players and the negative reaction of Serbian players, staff, and supporters to the content of the banner. CAS noted that, as follows from the practice associated with the misconduct of supporters (see TAS 2002/A/423 PSV Eindhoven / UEFA ${ }^{36}$, CAS 2007/A/1217

36 Database of CAS awards, TAS 2002/A/423 PSV Eindhoven / UEFA, http://jurisprudence.tascas.org/Shared\%20Documents/423.pdf [access: 10.12.2017]. 
Feyenoord Rotterdam v. UEFA, CAS 2013/A/3094 Hungarian Football Federation v. FIFA ${ }^{37}$, CAS 2013/A/3139), in the majority of cases undisciplined supporters were not personally identified. Therefore, a presumptive approach is used to determine whether or not an individual is considered to be a supporter of a given team, based on the perception of "a reasonable and objective observer".

In fact, there is rarely absolute certainty regarding whether the offender is an actual club's supporter or simply someone disguised as such. In accordance with this approach, it is for the association or club being charged by UEFA to rebut such a presumptive attribution by providing evidence to the contrary. In CAS 2015/A/3874, the appellant did not provide any evidence that would have indicated the possible participation of Serbian supporters in the incident with the drone and did not explain why Serbian supporters would have been interested in its control. The argument presented by the appellant, that the Albanian supporters could not control the drone since they were not found, was considered to be insufficient for two reasons. Firstly, CAS had already dealt with a similar situation in CAS 2013/A/3139, where flares were launched outside the stadium and parachuted onto the field, and the fact that the perpetrators could not be seen was irrelevant. Secondly, and decisively, often misbehaving supporters may not be individually identified even if they are inside the stadium. For example, they can hide behind others or cover their faces with scarves, bandanas, masks, etc. In view of the foregoing, CAS decided that the FAA was liable for the incident with the drone with an illicit banner.

\section{Concluding Remarks}

In the case CAS 2015/A/ 3874 the FAA did not provide any evidence that would have indicated the possible participation of Serbian supporters in the incident with the drone and did not explain why Serbian supporters would have been interested in controlling it. The jurisdiction bodies of UEFA and CAS do not consider convincing the argument of the national association or the club that some supporters could not have controlled the drone since they were not found at the stadium. Strict liability for the misbehavior of supporters is applied when supporters are present outside the stadium, or if it is impossible to identify them for other reasons (for example, when they hide their faces from cameras). Therefore, the consistent CAS practice (CAS 2002/A/423, CAS 2007/A/1217, CAS 2013/A/3094, CAS 2013/A/3139), which confirms that a presumptive approach which involves assessing the situation from the perspective of "a reasonable and objective observer", is justified. A national association or a club has the right to provide evidence refuting the affiliation of a supporter, and hence the charge. But such

37 CAS bulletin, CAS 2013/A/3094 Hungarian Football Federation v. FIFA, http://www.tas-cas. org/fileadmin/user_upload/Bulletin_2014_2.pdf [access: 10.12.2017]. 
a burden of proof is put on the team in respect of which there is a presumption of a supporter's affiliation based on the collected evidence. Otherwise, if there are no responsible individuals, no confession or other compelling evidence of the supporter's affiliation, it is practically impossible for UEFA to impose strict liability sanctions against national associations and clubs for the misbehavior of supporters.

Regulation of the strict liability of clubs by the Austrian Football Association is characterized by the "criminalization" of a smaller number of offenses. In particular, the offensive behavior of supporters before, during and after the match is not a basis for disciplinary proceedings against the club but allows the administrator to apply such an administrative measure as a ban on visiting stadiums under the jurisdiction of the association. However, any unacceptable behavior of supporters which violates the order at the match entail the use of the strict liability model of the organizing club or guest club in accordance with the rebuttable presumption that supporters belong to one of the two clubs participating in the match.

The use of the conception "a reasonable and objective observer" allows the legal bodies to answer a wide range of questions about the adequacy of the evidence presented by both parties. The legal bodies assess the presented evidence from the standpoint of the following conception: whether the event (the supporter's behavior) occurred, and whether such an event was lawful or not. However, the issue of the use of individual evidence (for example, $\mathrm{FARE}^{38}$ reports) as grounds for opening disciplinary proceedings, and the status of evidence, is assessed in different ways in the practices of the UEFA legal bodies. On the one hand, the FARE reports are equivalent to any report of a violation of the provisions of the UEFA regulations and therefore should be evaluated as the basis for prosecution, as CAS mentioned, "in all seriousness" ${ }^{39}$. On the other hand, the FARE reports, which do not have the presumption of accuracy and relevance in accordance with the provisions of the UEFA Disciplinary Regulations, can both be accepted and rejected as evidence. A conditional criterion for their approbation by a legal body is the accuracy of the proof provided (which makes it possible to determine whether the event that has taken place), the club affiliation of the persons involved, as well as the character of the behavior of the supporters that is unacceptable at a football match.

The problem of the sufficiency and accuracy of the evidence stimulates the formation of new models. Thus, the use of the model "a reasonable and objective observer" allows the UEFA jurisdictional body to answer three questions. Firstly, whether or not there

38 FARE - "Football Against Racism in Europe" organization.

39 In CAS 2013/A/3324\&3369 GNK Dinamo v UEFA it is noted that the FARE examination, although it does not have the presumption described in Art. 38 UEFA Disciplinary Regulations, but should be carefully analyzed by the UEFA legal bodies. See: Decisions issued by the Court of Arbitration for Sport in cases involving UEFA, CAS 2013/A/3324 GNK Dinamo v. UEFA and CAS 2013/A/3369 GNK Dinamo v. UEFA, http://www.uefa.com/MultimediaFiles/Download/uefaorg/CASdecisions/02/47/25/32/2472532_DOWNLOAD.pdf [access: 10.12.2017]. 
has been a violation of the provisions of the Disciplinary Regulations. Secondly, what is the nature of the supporter's behavior? Thirdly, are the supporters affiliated with the specific club that participated in the match? This model has been tested in the practice of CAS and has been repeatedly confirmed by arbitration decisions as consistent with the nature of the disciplinary liability of clubs. As we noted earlier, the use of the proof model "a reasonable and objective observer" allows legal bodies to abstract from the subjective orientation of the unacceptable behavior of the supporter and to assess this behavior from the point of view of an observer who is not familiar either with the motives of the supporters or with their intent with regard to a specific person or group of persons. Unlike UEFA, the Austrian Football Association refers to the rebuttable presumption of the supporters in the guest sector and other sectors of the stadium ${ }^{40}$. This presumption, spread at the level of regulation of national associations, is quite acceptable for determining the affiliation of the supporters with the club, but does not allow questions about establishing the fact of violation of regulations and qualifying unacceptable behavior of supporters to be answered. We assume that the national associations -members of UEFA - use their models of proof close to the "a reasonable and objective observer", but it is difficult to provide empirical evidence of such a model because of the lack of openaccess full-text solutions of the jurisdictions of such associations in disputes related to the strict liability of the clubs for the unacceptable behavior of supporters.

\section{Literature}

De Vlieger M.A., Racism in European football: going bananas? An analysis of how to establish racist behaviour by football supporters under the UEFA disciplinary regulations in light of the inflatable banana-case against Feyenoord, "International Sports Law Journal" 2016, vol. 15, issue 3-4, pp. 226-232.

Vasilyev I.A., Kashaeva A.A., The sporting responsibility of football clubs for offensive behavior of supporters on the basis of pp."e" p. 2 Art. 16 UEFA Disciplinary Regulations and Art. 112, Art. 116 Russian Football Union (RFU) Disciplinary Regulations, "Petersburg Lawyer" 2017, no. 2, pp. 60-73.

Act of the Russian Government on 16.12.2013 no. 1156 "Rules of conduct for supporters at official sports competitions",

CAS 2007/A/1217 Feyenoord Rotterdam v. UEFA,

CAS 2013/A/3094 Hungarian Football Federation v. FIFA, CAS 2013/A/3139 Fenerbahçe SK v. UEFA,

40 Like the Russian Football Union (RFU). See Art. 32 RFU Disciplinary Regulations, http://95.213.251.201/documents/1/592eb7ea75642.doc [access: 10.12.2017]. 
CAS 2013/A/3324 GNK Dinamo v. UEFA and CAS 2013/A/3369 GNK Dinamo v. UEFA,

CAS 2015/A/3874 Football Association of Albania v. the UEFA and the Football Association of Serbia,

Code of the Russian Federation on Administrative Offenses,

Court of Moscow region Appeal Decision no. 33-10571/2014,

Krasnodar FC supporters were banned for a year six to attend home games after a fight with the supporters Anzhi FC.

Legia Warszawa S.A., Decision of 3 February 2015, Case Law Control, Ethics and Disciplinary Body \& Appeals Body. Season 2015/2016. January 2015 - June 2015.

Manchester United FC, Decision of 19 May 2016, Case Law Control, Ethics and Disciplinary Body \& Appeals Body. Season 2015/2016. January 2016 - June 2016.

\section{SUMMARY}

\section{The Views of the Court of Arbitration for Sport and the Austrian Football Association on Legal Liability for the Conduct of Supporters}

The clubs legal responsibility for the behavior of supporters is used by UEFA to influence the content of sports competitions, ideally abstracted from demonstrating by spectators any non-football ideas. Nevertheless, the regulation of the national associations-members of UEFA also assumes the responsibility of the clubs and, sometimes, the supporters themselves for the unacceptable behavior of the latter. The experience of regulation this issue by the Austrian Football Association demonstrates mentioned approach. Therefore, it is interesting to make a comparison: how much the regulated responsibility of supporters affects to the regulation by the association a strict liability of clubs for the behavior of fans. Using the practice of CAS, we may see a presumptive approach on the basis of an assessment of the situation by "a reasonable and objective observer" for the objective resolution of a dispute.

Keywords: strict liability, illegal behavior of supporters, legal liability of football clubs

Ilya Vasilyev, Saint Petersburg State University, Saint Petersburg, 7/9 Universitetskaya, Russian Federation, e-mail: i.vasilev@spbu.ru.

Margarita Izmalkova, Independent Researcher, Chuvash Republic, Cheboksary, Heves 1, e-mail: izm-margarita@yandex.ru.

Raisa Khalatova, Independent Researcher, Saint Petersburg, Stachek 55, Russian Federation, e-mail: halri2halri@gmail.com. 
